\title{
OnabotulinumtoxinA Improves Quality of Life in Chronic Migraine: The PREDICT Study
}

\author{
Guy Boudreau, Ian Finkelstein, Corrie Graboski, May Ong, Suzanne Christie, \\ Katherine Sommer, Meetu Bhogal, Goran Davidovic, Werner J. Becker
}

\begin{abstract}
Background: The PREDICT study assessed real-world, long-term health-related quality of life in adults with chronic migraine (CM) receiving onabotulinumtoxinA. Methods: Canadian, multicenter, prospective, observational study in adults naïve to onabotulinumtoxinA for CM. OnabotulinumtoxinA (155-195 U) was administered every 12 weeks over 2 years ( $\leq 7$ treatment cycles). Primary endpoint: mean change in Migraine-Specific Quality of Life Questionnaire (MSQ) at treatment 4 (Tx4) versus baseline. Secondary endpoints: mean change in MSQ at final visit versus baseline, and headache days. Results: 184 participants (average age 45 years; $84.8 \%$ female; $94.6 \%$ Caucasian) received $\geq 1$ onabotulinumtoxinA treatment; 150 participants completed 4 treatments (1 year) and 123 completed all 7 treatment cycles (2 years). Mean (SD) onabotulinumtoxinA dose per treatment cycle was 171 (18) U and treatment interval was 13.2 (1.8) weeks. Baseline mean (SD) 20.9 (6.7) headache days/month decreased (Tx1: -3.5 [6.3]; Tx4: -6.5 [6.6]; $p<0.0001$ versus baseline). Mean (SD) increased from baseline in MSQ at Tx4 (restrictive: 21.5 [24.3], preventive: 19.5 [24.7], emotional: 22.9 [32.9]) and the final visit (restrictive: 21.3 [23.0], preventive: 19.2 [23.7], emotional: 27.4 [30.7]), exceeding minimal important differences (all $p<0.0001$ ). Seventy-seven $(41.8 \%)$ participants reported 168 treatment-emergent adverse events (TEAEs); 38 TEAEs $(12.0 \%)$ were considered treatment-related. Four (2.2\%) participants reported six serious TEAEs; none were considered treatment-related. No new safety signals were identified. Conclusions: Real-world evidence from PREDICT demonstrates that onabotulinumtoxinA for CM in Canada improved MSQ scores and reduced headache frequency and severity, adding to the body of evidence on the long-term safety and effectiveness of onabotulinumtoxinA for CM.
\end{abstract}

RÉSUMÉ : La toxine botulinique de type A améliore la qualité de vie des personnes souffrant de migraine chronique : résultats de l'étude PREDICT. Contexte : L'étude PREDICT visait à évaluer la qualité de vie liée à la santé sur une longue période, fondée sur des données factuelles, chez des adultes souffrant de migraine chronique (MC) et recevant la toxine botulinique de type A. Méthode : Il s'agit d'une étude d'observation, prospective, multicentrique, réalisée au Canada, chez des adultes jamais traités par la toxine pour la MC. La substance (155-195 U) a été administrée toutes les 12 semaines, sur une période de 2 ans ( $\leq 7$ séances de traitement). Le principal critère d'évaluation était la variation moyenne des scores au Migraine-Specific Quality of Life Questionnaire (MSQ) au 4 traitement (tt) par rapport (p/r) à la valeur initiale; les critères d'évaluation secondaires, eux, consistaient en la variation moyenne du score au MSQ à la dernière consultation p/r à la valeur initiale ainsi que du nombre de jours avec maux de tête. Résultats : Au total, 184 participants (âge moyen : 45 ans; femmes : 84,8 \%; race blanche : 94,6\%) ont été soumis à $\geq 1$ traitement par la toxine; sur ce nombre, 150 ont reçu 4 traitements ( 1 an) et 123 , les 7 traitements ( 2 ans). La dose moyenne (écart-type $: \sigma$ ) de toxine par traitement était de 171 U (18) et l'intervalle entre les traitements, de 13,2 semaines $(\sigma: 1,8)$. Le nombre moyen $(\sigma)(20,9[6,7])$ initial de jours/mois avec maux de tête a connu une diminution $\left(1^{\text {er }}\right.$ tt : $-3,5[6,3]$; $4^{\mathrm{e}} \mathrm{tt}:-6,5[6,6] ; p<0,0001 \mathrm{p} / \mathrm{r}$ à la valeur initiale). En revanche, une augmentation du score moyen $(\sigma)$ initial au MSQ a été enregistrée au $4^{\mathrm{e}}$ tt (limites : 21,5 [24,3], prévention : 19,5 [24,7], émotions : 22,9 [32,9]) ainsi qu'à la dernière consultation (limites : 21,3 [23,0], prévention : 19,2 [23,7], émotions : 27,4 $[30,7])$, ce qui représente des valeurs supérieures à l'écart significatif minimal (toutes les valeurs de $p<0,0001)$. Par ailleurs, 77 participants $(41,8 \%$ ) ont fait état de 168 événements indésirables (EI) apparus depuis le début du traitement, dont $38(12,0 \%)$ ont été considérés comme liés au traitement. Quatre participants $(2,2 \%)$ ont aussi déclaré 6 nouveaux EI d'importance, mais pas un de ces derniers n'a été considéré comme lié au traitement. Aucun nouveau problème d'innocuité n'a été mis en évidence. Conclusion : D'après les données probantes et factuelles de l'étude $P R E D I C T$, la toxine botulinique de type A dans le traitement de la MC au Canada a permis une amélioration des scores au MSQ ainsi qu'une diminution de la fréquence et de l'intensité des maux de tête, ce qui ajoute au faisceau d'arguments sur l'innocuité à long terme et l'efficacité de la substance dans ce contexte.

Keywords: Botulinum toxin, Headache, Patient-reported outcome, Preventive, Satisfaction, Utilization

doi:10.1017/cjn.2021.153

Can J Neurol Sci. 2022; 49: 540-552

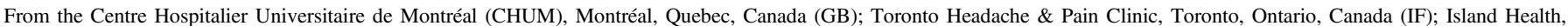

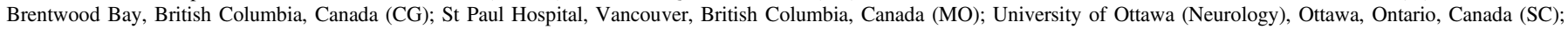

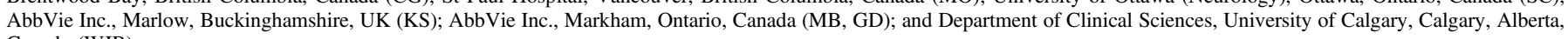
Canada (WJB)

Received January 29, 2021. Final Revisions Submitted June 23, 2021. Date of Acceptance June 26, 2021.

Correspondence to: Dr. Guy Boudreau, CHUM Research Centre, 900, Saint Denis Street, Pavillon R, Montreal, Quebec, Canada H2X 0A9. Email: boudreau.guyp@ gmail.com 


\section{INTRODUCTION}

Chronic migraine (CM) is a neurological disease defined by the International Classification of Headache Disorders, third edition (ICHD-3, beta version) as having fifteen or more headache days/month for more than three months over a twelve month period, with at least eight headaches per month fulfilling the criteria for migraine with or without aura. ${ }^{1}$ In Canada, the prevalence of CM is estimated at 392,000 to 600,000 based on the global prevalence of $1.4 \%-2.2 \%{ }^{2,3}$ In comparison to those with episodic migraine, defined as $<15$ headache days per month, individuals with $\mathrm{CM}$ have higher rates of medical and psychiatric comorbidities, greater headache-related disability, increased health resource utilization, and lower socioeconomic status. ${ }^{4} \mathrm{CM}$ can adversely affect health-related quality of life and daily functioning, ${ }^{4-6}$ resulting in social and economic burdens. ${ }^{7,8}$ This burden of illness is apparent in feedback provided by Migraine Canada as part of the Canadian Agency for Drugs and Technologies in Health process, where patient narratives and experiences were collected as part of a survey. ${ }^{9}$ Among Canadian patients with CM, 45\% indicated they were disabled and unable to work because of their $\mathrm{CM}$ and an additional 52\% reported missing some or many days of work due to headaches. Furthermore, respondents indicated that their migraine attacks put strain on their marriage, family life, and mental health. Patient input also indicated that currently available treatments are insufficient and poorly tolerated, with over $75 \%$ of respondents reporting side effects severe enough to discontinue their medication and $31 \%$ stopping $\geq 4$ drugs due to adverse events (AEs).

$\mathrm{CM}$ is an underdiagnosed and often undertreated disease, ${ }^{10,11}$ with fewer than 5\% of those with CM traversing all three steps essential to good medical care: consulting a headache professional, receiving an accurate diagnosis, and being prescribed appropriate treatment. ${ }^{12}$ Pharmacological management of $\mathrm{CM}$ includes acute treatment of migraine attacks with abortive medication(s), as well as preventive treatment(s) to reduce the frequency and severity of headache days while minimizing adverse side effects. ${ }^{13-15}$ Although a variety of pain medications are effective for the acute treatment of migraine attacks, prolonged use can lead to medication overuse headache, ${ }^{16-18}$ emphasizing the importance of preventive $\mathrm{CM}$ treatments to reduce the need for these interventions. ${ }^{15}$ Preventive treatments typically utilized for CM include anticonvulsants (gabapentin, topiramate, valproate), antidepressants/muscle relaxants (amitriptyline, tizanidine), beta-blockers (propranolol, metoprolol, timolol), and/or onabotulinumtoxin $\mathrm{A},{ }^{19,20}$ and more recently anti-calcitonin generelated peptide monoclonal antibodies (anti-CGRP $\mathrm{mAbs}^{21-23}$ ).

OnabotulinumtoxinA (BOTOX ${ }^{\oplus}$; Allergan plc, Dublin, Ireland) is approved worldwide as a preventive treatment for adults with CM. It is believed that extracranial administration of onabotulinumtoxinA reduces the number of pain signals that reach the brain through mechanisms that inhibit sensory nerve endings, thereby preventing the activation and sensitization of neurons believed to be involved in migraine chronification. OnabotulinumtoxinA suppresses the release of proinflammatory and excitatory neurotransmitters and neuropeptides (e.g., CGRP, glutamate, and substance P), decreases the insertion of painsensitive ion channels (e.g., transient receptor potential cation channel subfamily $\mathrm{V}$ member 1) into the membranes of nociceptive neurons, and prevents and reverses sensitization in nociceptive sensory neurons. ${ }^{24}$ Results from the Phase III Research Evaluating Migraine Prophylaxis Therapy (PREEMPT) clinical program established that onabotulinumtoxin $\mathrm{A}$ is an effective and well-tolerated preventive for CM over an approximately one-year period. ${ }^{25-28}$ Recent publications from the COMPEL $^{29}$ and REPOSE ${ }^{30}$ studies have provided additional long-term data on the safety and efficacy of onabotulinumtoxinA for the prevention of headaches in adults with $\mathrm{CM}$ in a clinical setting. However, these studies focused predominately on US, Korean, and Australian (COMPEL) and European (REPOSE) populations, and therefore, there remains a need for real-world evidence on the effects of onabotulinumtoxinA treatment for $\mathrm{CM}$ within Canada. The PREDICT study was designed to prospectively assess real-world, long-term health-related quality of life in adults with CM treated with onabotulinumtoxinA using physician- and patient-reported outcomes in a real-world design over an approximately two-year period in Canada. ${ }^{31,32}$

\section{Methods}

\section{Study Design}

PREDICT is a Canadian, multicenter, prospective, observational standard of care study (NCT02502123). Data were collected by fifteen physicians across sixteen headache/pain centers in Canada, including two sites in Alberta, four sites in British Columbia, six sites in Ontario, and three sites in Quebec. The target population size for this study, which was collected using a convenience sample based on clinical and practical considerations, was 200 participants. Assuming a dropout rate of $\sim 10 \%$, it was anticipated that the remaining sample size would be sufficient to meet the study objectives. Study participants were recruited during routine clinical practice.

The PREDICT study design included a four-week baseline period with screening at visit 1 , followed by an observation period where onabotulinumtoxinA was administered at treatment visits, and a final visit at the end of the study. For individuals that discontinued the study, their last visit prior to discontinuation was considered the final visit for analysis purposes.

For participants who met the screening criteria and completed the baseline period, it was recommended that onabotulinumtoxinA treatments be administered every twelve weeks per the Canadian onabotulinumtoxinA product monograph (version July $7,2014^{33}$ ) over the two-year treatment period. Based on the PREEMPT paradigm, ${ }^{31,32} 155 \mathrm{U}$ of onabotulinumtoxinA was administered as thirty-one fixed-site, fixed-dose intramuscular injections across seven specific head/neck muscle areas. If a predominant pain location(s) was reported, the recommended dosage could be adjusted with optional additional injections to one or both sides in up to three specific muscle groups (temporalis, occipitalis, and trapezius), for a total dose of $195 \mathrm{U}$ of onabotulinumtoxinA administered to 39 sites per treatment. As this was an observational study, no control group was utilized. The PREEMPT paradigm was not monitored, and physicians could deviate from these recommendations. Financial support was not provided to the study participants for any treatment/ treatment-related costs, and onabotulinumtoxinA was accessed per the participants' usual means for obtaining prescription medications. 
PREDICT was conducted in accordance with all relevant regulatory guidelines, including the International Conference on Harmonisation Guideline for Good Clinical Practice. Approval of the study protocol was obtained by each investigator from a properly constituted Research Ethics Board (REB) prior to initiating the study.

\section{Participants}

Adults (male or female; $\geq 18$ years of age) with $\mathrm{CM}$ as defined by the ICHD-3, beta version ${ }^{1}$ who were eligible to receive onabotulinumtoxinA per the approved Product Monograph ${ }^{33}$ were included in this study. Participants were permitted to use medication(s) with a known preventive effect as long as the dose was stable and the medication(s) well-tolerated for at least twelve weeks prior to the screening visit. Regarding acute treatment for migraine attacks, participants currently taking or planning on taking opioid-containing products, barbiturates, or opioid-barbiturate combination therapies for acute headache treatment or a pain condition on more than $8 \mathrm{~d}$ during the baseline period were excluded. All study participants were naïve to onabotulinumtoxinA treatment for $\mathrm{CM}$ at baseline, and onabotulinumtoxinA treatment was deemed medically necessary by the participating physician independently from this study. Participants with severe depression were excluded out of concern for their ability to complete a trial of long duration. A complete list of inclusion and exclusion criteria is provided in Supplemental Table 1. All participants were asked to read and voluntarily sign an REB-approved informed consent form prior to enrollment in the study or undergoing any study-related procedures.

\section{Outcomes and Data Sources}

The primary endpoint in PREDICT was the mean change in Migraine-Specific Quality of Life Questionnaire $\left(\mathrm{MSQ}^{34-36}\right)$ at treatment 4 (Tx4) compared with MSQ at baseline (visit 1) in adults with CM treated with onabotulinumtoxinA. The MSQ is a fourteen-item questionnaire designed to measure health-related quality-of-life impairments attributed to migraine in the past four weeks. The questionnaire is divided into three domains: 1) role function restrictive-assesses how migraine limits one's daily social and work-related activities, 2) role function preventiveassesses how migraine prevents these activities, and 3) emotional function-assesses the emotions associated with migraines. Study participants responded to each item using a six-point Likert-type scale with responses ranging from "none of the time" (1) to "all of the time" (6). Raw dimension scores were computed as a sum of item responses and rescaled to a 0-100 scale, where higher scores indicate better quality of life. The change in score that represents the minimal important difference (MID) for role restrictive is 10.9 , for role preventive is 8.3 , and for emotional function is $12.2 .^{37}$

To further understand the long-term effects of onabotulinumtoxinA treatment, secondary endpoints relating to health-related quality of life and treatment satisfaction and tolerability were also measured. The mean change in MSQ between the final study visit and baseline was assessed as described above. OnabotulinumtoxinA treatment utilization (i.e., treatment intervals and dosages used) was evaluated at several time points and for the overall study. The dose of onabotulinumtoxinA and treatment patterns were documented by study investigators on case report forms at each study visit where treatment was administered and verified with source documents by a study monitor. In addition, participants completed a daily headache diary for all weeks of the study that aimed to quantify headache frequency and severity between study visits. The Subject Headache Diary was distributed to the participants at Visits 1 (Screening) through 6 and collected at Visits 2 through 7. Participants documented their headaches in their headache diary during the four-week screening period to establish the baseline monthly headache frequency and severity (rated as mild, moderate, or severe). Data were stratified by those experiencing a moderate or severe headache day, defined as a severity score $\geq 5$ based on daily headache diary entries.

Both participant and physician satisfaction with onabotulinumtoxinA treatment were evaluated throughout the study. At Visits 3 through 7, participants completed the patient global assessment of treatment questionnaire, which consists of a series of statements rated on a five-point Likert-type scale about the impact of treatment on headache symptoms and activities of daily living, including items regarding treatment satisfaction. At Visit 5/Tx4 and Visit 7/Final Visit study physicians completed the Clinician Global Impression of Change (CGIC) to provide a global impression of change in the participant's health. This instrument asked physicians to rate the following question: "Compared to the participant's condition at admission to the study, how much has he or she changed?" on a seven-point scale, with $1=$ "very much improved" and $7=$ "very much worse."

At each study visit, the investigator asked participants about adverse experiences that may have occurred since signing the informed consent. All AEs were recorded, including the severity, action taken, and relationship to onabotulinumtoxinA treatment. Treatment-emergent AEs (TEAEs) with a reasonable relationship to onabotulinumtoxinA treatment were summarized by presenting overall counts and percentages in each system organ class by preferred term. TEAEs leading to discontinuation of onabotulinumtoxinA treatment were also summarized. Data collection time points and a brief description of each measure are included in Supplemental Table 2.

Five inclusion and 15 exclusion criteria were applied during participant enrollment to minimize selection bias and confounding. Headache diaries were completed daily by the study participants, and collected monthly by the investigators, to limit information/recall bias. To further reduce information bias, site investigators and personnel were trained on the approved protocol, Good Clinical Practices, regulatory requirements, and $\mathrm{AE}$ reporting.

\section{Quantitative Variables and Statistical Methods}

This is the primary analysis of the PREDICT study data. This study was observational only; no formal hypothesis was tested, and no formal sample size calculations were performed. Data from all clinical sites were combined for analysis. Descriptive statistics were calculated for continuous variables (number of observations, mean, standard deviation [SD], ranges) and categorical variables (frequencies, percentages). The primary endpoint analysis of change from baseline at Tx4 for each MSQ domain and the secondary endpoint of change from baseline at final visit for each MSQ domain were conducted using a twosided paired $t$-test at the two-sided 0.05 significance level. The analysis of the secondary endpoint of change from baseline in 


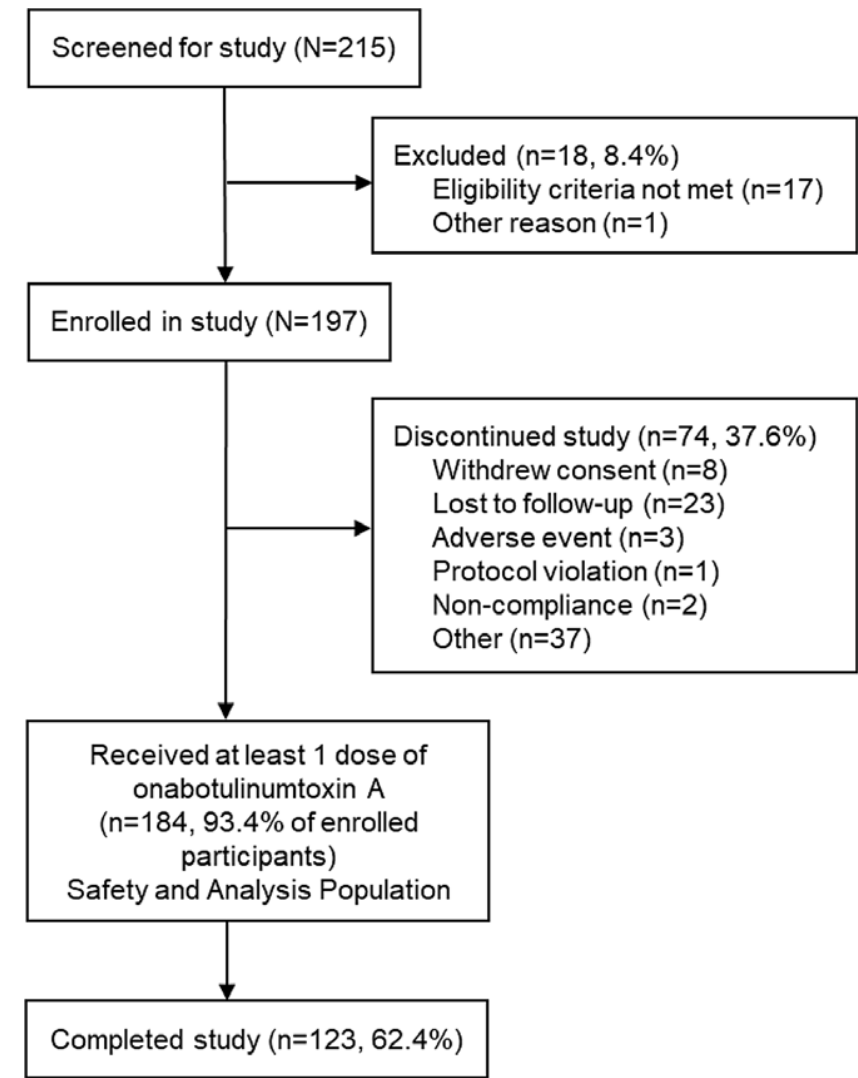

Figure 1: PREDICT study participant disposition.

Diagram of PREDICT study participant disposition, with the number of participants who were excluded from the study and the number of participants that withdrew from the study shown. No data were missing. $n$ or $N$, the number of participants.

headache days was conducted using a two-sided Wilcoxon matched pairs signed-rank test. $P$-values were not adjusted for multiple comparisons. Data were analyzed as observed, with no imputation for missing values, except for MSQ domain scores and calculation of headache days per month. If one or more items within an MSQ dimension were missing, the value for that item was estimated based on the average of the other items within the same dimension. For headache diary counts, participants with fewer than $15 \mathrm{~d}$ of diary data available for days 57 through 84 analysis windows were set to missing. A prorated approach was used to standardize the original count to a 28 -day count for observed data, and no additional imputation was applied. The analysis population included all study participants who received $\geq 1$ treatment with onabotulinumtoxinA. All participant data are shown for each treatment visit until they discontinued the study or were lost to follow-up. Sensitivity analyses were performed for primary and secondary endpoints including the subgroup of individuals who completed all seven treatment cycles (referred to as study completers hereafter; $n=123$ ). Statistical analyses were conducted using $\mathrm{SAS}^{\oplus}$ Version 9.2 on a PC platform.

\section{Results}

\section{Participant Disposition}

PREDICT (study dates: July 3, 2015 to January 29, 2019) screened a total of 215 individuals with CM (Figure 1). Of these,
$18 / 215$ (8.4\%) were excluded from the study due to failures during screening at baseline, and 197/215 (91.6\%) were enrolled in the study. The mean $( \pm \mathrm{SD})$ number of months that participants were enrolled in the study was $17.9( \pm 7.0)$ with a range of 0 to 29.5 months.

The PREDICT study enrolled 197 participants, and 184 of these participants received at least one treatment with onabotulinumtoxinA. These 184 individuals comprise the analysis population and are reported on hereafter in the manuscript. Of the enrolled participants, 123/197 (62.4\%) completed the two-year study (seven injection cycles) and 74/197 (37.6\%) discontinued the study (Figure 1). The majority of participants who discontinued the study $(61 / 74 ; 82 \%)$ completed a withdrawal questionnaire providing the reason(s) for discontinuation. The most common reasons cited in the withdrawal questionnaire for early discontinuation were "treatment did not work" $(23 / 184 ; 12.5 \%)$ and "cost of injection treatment" $(5 / 184 ; 2.7 \%)$. A full list of reasons for study discontinuation is provided in Supplemental Table 3.

\section{Baseline Demographics, CM History, and Medication Use History}

Participant demographic and clinical characteristics are presented in Table 1. At baseline, study participants were, on average, 45 years of age, predominantly female $(156 / 184 ; 84.8 \%)$ and Caucasian $(174 / 184 ; 94.6 \%)$. Participants reported a mean (SD) of 23 (6) headache days per month in the previous three months. On average, participants started having fifteen or more headache days per month at mean (SD) 34 (14) years of age but were not diagnosed with CM until mean (SD) 39 (15) years of age, equaling a nearly five-year delay. More than half of the participants (110/ $182 ; 60.4 \%$ ) self-reported a family history of CM.

The majority of participants $(173 / 184 ; 94.0 \%)$ reported taking an acute medication for CM in the past three months, with acute medication use on a mean (SD) of 17 (9) days per month in the past three months. Simple analgesics $(128 / 173 ; 74.0 \%)$ and triptans $(128 / 173 ; 74.0 \%)$ were the most frequently reported type of acute medication. In addition, the majority of participants (145/ $184 ; 78.8 \%$ ) reported taking preventive medication for $\mathrm{CM}$ in the past two years. Antidepressants $(90 / 184 ; 62.1 \%)$ and anticonvulsants $(81 / 184 ; 55.9 \%)$ were the most frequently reported types of preventive medication.

\section{OnabotulinumtoxinA Treatment Utilization}

Consistent with the product monograph's recommendation to administer onabotulinumtoxinA treatment every twelve weeks, ${ }^{33}$ the mean (SD) treatment interval across treatment visits 1-4 $(\mathrm{n}=487$ treatments) was 13.2 (1.8) weeks (Table 2A). Across all treatments, the mean (SD) total dose of onabotulinumtoxinA used per participant per treatment visit was 171 (18) U, which is consistent with dosing used for each individual session as well (Table 2B). The distribution of participants receiving $<155 \mathrm{U}$, 155-195 U, $>195-200 \mathrm{U}$, or $>200 \mathrm{U}$ is also shown in Table 2B, demonstrating that at $>75 \%$ of treatment sessions throughout the PREDICT study, participants received between 155-195 U of onabotulinumtoxinA; $>18 \%$ received $195-200 \mathrm{U}$. This is in alignment with onabotulinumtoxinA dosing stated in the Canadian product monograph (version July 7, 2014 ${ }^{33}$ ) and the PREEMPT paradigm. $^{31,32}$ 
Table 1: Baseline participant demographics, chronic migraine history, and medication use history ${ }^{\dagger}$

\begin{tabular}{|c|c|}
\hline & $(n=184)$ \\
\hline \multicolumn{2}{|l|}{ Age (years) } \\
\hline Mean (SD) & $44.8(12.1)$ \\
\hline Min, Max & $19.0,72.0$ \\
\hline \multicolumn{2}{|l|}{ Gender, n (\%) } \\
\hline Female & $156(84.8)$ \\
\hline Male & $28(15.2)$ \\
\hline \multicolumn{2}{|l|}{ Race, n (\%) } \\
\hline Caucasian & 174 (94.6) \\
\hline Asian & $5(2.7)$ \\
\hline Latin American & $3(1.6)$ \\
\hline Aboriginal & $1(0.5)$ \\
\hline Other & $1(0.5)$ \\
\hline \multicolumn{2}{|l|}{ Age at diagnosis with CM (years) } \\
\hline $\mathrm{n}$ (missing) & $178(6)$ \\
\hline Mean (SD) & $38.6(14.6)$ \\
\hline Min, Max & $5.0,73.0$ \\
\hline \multicolumn{2}{|l|}{$\begin{array}{l}\text { Age started having headaches }>15 \\
\text { d/month (years) }\end{array}$} \\
\hline $\mathrm{n}$ (missing) & $178(6)$ \\
\hline Mean (SD) & $34.4(13.5)$ \\
\hline Min, Max & $4.0,69.0$ \\
\hline \multicolumn{2}{|l|}{$\begin{array}{l}\text { Average number of headache days/month } \\
\text { in the past three months (days) }\end{array}$} \\
\hline Mean (SD) & $23.1(5.7)$ \\
\hline Min, Max & $12.0,30.6$ \\
\hline \multicolumn{2}{|l|}{ Family history of CM, n (\%) } \\
\hline $\mathrm{n}$ (missing) & $182(2)$ \\
\hline Yes & $110(60.4)$ \\
\hline No & $72(39.6)$ \\
\hline \multicolumn{2}{|l|}{$\begin{array}{l}\text { On average, over the past three months, } \\
\text { how many days per month did } \\
\text { participant take acute medication for } \\
\mathrm{CM}, \mathrm{n}(\%)\end{array}$} \\
\hline $\mathrm{n}$ (missing) & $183(1)$ \\
\hline Mean (SD) & $16.8(9.0)$ \\
\hline Min, Max & $0.0,30.0$ \\
\hline \multicolumn{2}{|l|}{$\begin{array}{l}\text { Participant has taken acute/abortive } \\
\text { medications for } \mathrm{CM} \text { in the past three } \\
\text { months, } \mathrm{n}(\%)\end{array}$} \\
\hline No & $11(6.0)$ \\
\hline Yes $^{\frac{1}{3}}$ & $173(94.0)$ \\
\hline Simple analgesics & $128(74.0)$ \\
\hline Triptans & $128(74.0)$ \\
\hline Combination opioid analgesics & $30(17.3)$ \\
\hline \multicolumn{2}{|l|}{$\begin{array}{l}\text { Participant has taken preventive } \\
\text { medications for CM in the past two } \\
\text { years, } \mathrm{n}(\%)\end{array}$} \\
\hline No & 39 (21.2) \\
\hline
\end{tabular}

Table 1: (Continued)

\begin{tabular}{l|c}
\hline & $(\mathbf{n}=\mathbf{1 8 4})$ \\
\hline Yes $^{\ddagger}$ & $145(78.8)$ \\
\hline Antidepressants & $90(62.1)$ \\
\hline Anticonvulsants & $81(55.9)$ \\
\hline Beta-blockers & $44(30.3)$
\end{tabular}

$\overline{\mathrm{CM}}$, chronic migraine; max, maximum; min, minimum; $\mathrm{n}$, number of participants; SD, standard deviation

${ }^{\dagger}$ Missing data include: six participants for age at diagnosis and age participant started having headaches, two participants for family history, and one participant for days per month acute medication

${ }^{\ddagger}$ The top three most frequently used medication types are shown

\section{Effectiveness}

\section{Migraine-Specific Quality of Life Questionnaire (MSQ)}

At baseline, the mean (SD) score for each MSQ domain (on a total scale of 0-100 for each domain, with higher scores indicating better quality of life) was as follows: role restrictive 36.4 (17.8), role preventive 50.8 (23.0), and emotional function 38.4 (27.8). To assess the primary endpoint for PREDICT, mean change in MSQ score from baseline to Tx4 was assessed for each domain. At baseline and Tx4, respectively, mean (SD) MSQ role restrictive domain scores were 36.4 (17.8) and 58.4 (22.4); role preventive scores were 50.8 (23.0) and 70.5 (24.1); and emotional function scores were 38.4 (27.8) and 61.6 (30.4), with $p<0.0001$ for all Tx4 values versus baseline. Across all domains, study participants reported significantly higher MSQ scores at Tx4 than at baseline (all comparisons $p<0.0001$ ), indicating improved quality of life following onabotulinumtoxinA treatment (Figure 2A). Similarly, study participants treated with onabotulinumtoxinA reported significantly higher MSQ scores across all domains at the final visit than at baseline. Mean (SD) domain scores at final visit for role restrictive was 58.1 (22.6); for role preventive was 70.8 (22.4); and for emotional function was 64.7 (28.5), with $p<0.0001$ for all final visit values versus baseline (all comparisons, $p<0.0001$; Figure 2A), indicating that these individuals continued to have quality of life improvements throughout the course of the study. Mean (SD) changes from baseline at Tx4 and Final Visit, respectively, for MSQ role restrictive were 21.5 (24.3) and 21.3 (23.0); for role preventive were 19.5 (24.7) and 19.2 (23.7); and for emotional function were 22.9 (32.9) and 27.4 (30.7). All changes in MSQ scores exceeded the within-group MIDs established for each domain (Figure 2B). ${ }^{37}$ The interpretation of the results did not change with $p$-value adjustment for multiple comparisons.

Participants that completed the study $(\mathrm{n}=123)$ reported similar MSQ domain scores at baseline as the total participant population (mean $[\mathrm{SD}]$ role restrictive $[\mathrm{n}=123]$ : 37.4 [19.0], role preventive [ $\mathrm{n}=123$ ]: 51.9 [23.8], and emotional function $[\mathrm{n}=123]$ : 37.2 [27.3]). Following onabotulinumtoxinA treatment, study completers reported statistically significant increases from baseline in MSQ scores across all domains at Tx4 (mean [SD] role restrictive $[\mathrm{n}=123]$ : 59.9 [22.1], role preventive [ $\mathrm{n}=123$ ]: 73.1 [22.5], and emotional function $[\mathrm{n}=123]$ ]: 63.0 $[30.2]$ ) and at the final visit (mean $[\mathrm{SD}]$ role restrictive $[\mathrm{n}=121]$ : 
Table 2: OnabotulinumtoxinA treatment interval (A) and dosage (B)

\begin{tabular}{|c|c|c|c|c|c|c|}
\hline $\mathbf{A}$ & $\begin{array}{c}\text { Tx1 to } \mathbf{T x} 2 \\
(\mathrm{n}=174)\end{array}$ & \multicolumn{2}{|c|}{$\begin{array}{c}T \times 2 \text { to } T \times 3 \\
(n=163)\end{array}$} & $\begin{array}{c}\text { Tx3 to } \mathbf{T x 4} \\
(n=150)\end{array}$ & $\begin{array}{c}\text { All Tx } \\
(\mathbf{T x 1}-\mathbf{T} \times 4) \\
(\mathrm{n}=\mathbf{4 8 7})\end{array}$ & $\begin{array}{l}\text { Tx7 to } \\
\text { Final Visit } \\
(\mathbf{n}=\mathbf{1 2 8})\end{array}$ \\
\hline \multicolumn{7}{|l|}{ Interval, weeks } \\
\hline Mean (SD) & $13.1(1.7)$ & \multicolumn{2}{|c|}{$13.1(1.3)$} & $13.5(2.4)$ & $13.2(1.8)$ & $14.1(3.7)$ \\
\hline Median & 13.0 & \multicolumn{2}{|c|}{13.0} & 13.0 & 13.0 & 13.1 \\
\hline Q1, Q3 & $12.0,14.0$ & \multicolumn{2}{|c|}{$12.0,13.9$} & $12.0,14.0$ & $12.0,14.0$ & $12.4,14.1$ \\
\hline Min, Max & $8.9,22.9$ & \multicolumn{2}{|c|}{$10.0,19.0$} & $11.0,25.6$ & $8.9,25.6$ & $0.1,31.6$ \\
\hline \multicolumn{7}{|l|}{ Interval, n (\%) } \\
\hline$<12$ weeks & $27(15.5)$ & \multicolumn{2}{|c|}{$17(10.4)$} & $14(9.3)$ & $58(11.9)$ & $6(4.7)$ \\
\hline 12 weeks & $25(14.4)$ & \multicolumn{2}{|c|}{$29(17.8)$} & $20(20.0)$ & $84(17.2)$ & $20(15.6)$ \\
\hline$>12$ weeks & $122(70.1)$ & $117(71.8)$ & \multicolumn{2}{|c|}{$106(70.7)$} & $345(70.8)$ & $102(79.7)$ \\
\hline B & $\begin{array}{c}\text { Tx1 } \\
(n=184)\end{array}$ & $\begin{array}{c}\text { Tx2 } \\
(n=174)\end{array}$ & $\begin{array}{c}\text { Tx3 } \\
(n=163)\end{array}$ & $\begin{array}{c}\text { Tx4 } \\
(n=150)\end{array}$ & $\begin{array}{c}\mathbf{T x 7} \\
(\mathrm{n}=\mathbf{1 2 8})\end{array}$ & $\begin{array}{c}\text { All Tx } \\
(n=799)\end{array}$ \\
\hline \multicolumn{7}{|l|}{ Total dose, $\mathrm{U}$} \\
\hline Mean (SD) & $171(18)$ & $171(19)$ & $172(18)$ & $170(18)$ & $171(19)$ & $171(18)$ \\
\hline Median & 165 & 165 & 170 & 165 & 170 & 165 \\
\hline Q1, Q3 & 155,190 & 155,185 & 155,185 & 155,185 & 155,185 & 155,185 \\
\hline Min, Max & 155,210 & 125,255 & 140,255 & 125,200 & 135,250 & 125,255 \\
\hline \multicolumn{7}{|c|}{ Total dose, $\mathrm{n}(\%)$} \\
\hline$<155 \mathrm{U}$ & $0(0.0)$ & $4(2.3)$ & $1(0.6)$ & $3(2.0)$ & $2(1.6)$ & \\
\hline $155-195 \mathrm{U}$ & $141(76.6)$ & $132(75.9)$ & $126(77.3)$ & $115(76.7)$ & $100(78.1)$ & \\
\hline$>195-200 \mathrm{U}$ & $42(22.8)$ & $36(20.7)$ & $34(20.9)$ & $32(21.3)$ & $23(18.0)$ & \\
\hline$>200 \mathrm{U}$ & $1(0.5)$ & $2(1.1)$ & $2(1.2)$ & $0(0.0)$ & $3(2.3)$ & \\
\hline
\end{tabular}

Max, maximum; min, minimum; n, number of treatments; Q1, quartile 1; Q3, quartile 3; SD, standard deviation; TX, treatment; U, units.

†No data were missing.

${ }^{\ddagger}$ Data shown represent the average of Tx1 to Tx2, Tx2 to Tx3, and Tx3 to Tx4.

60.1 [22.4], role preventive [ $\mathrm{n}=121$ ]: 71.9 [22.3], and emotional function [n=120]: 67.0 [28.1]) (all comparisons, $p<0.0001$ ); meeting MIDs for all domains.

\section{Headache Days}

During the baseline period, participants self-reported a mean (SD) of 20.9 (6.7) headache days/month in their daily headache diary (Figure 3A). Following onabotulinumtoxinA treatment, the number of self-reported headache days per month was reduced (Figure 3B). At Tx4, study participants reported an average of 6.5 fewer headache days than at baseline, with all time points showing statistical significance (all comparisons versus baseline, $p<0.0001)$. Study completers reported a slightly lower number of headache days per month at baseline (20.1 [6.7]), but experienced similar or slightly higher reductions in headache days following onabotulinumtoxinA treatment $(\mathrm{Tx} 1[\mathrm{n}=109]$ : -3.9 [6.3], Tx2 [n=107]: -4.9 [6.6], Tx3 [n=110]: -5.4 [6.8], Tx4 [n=107]: -6.5 [6.5], Tx7/Final Visit $[n=103]:-6.5$ [7.2]), which were statistically significant compared with baseline (all comparisons, $p<0.0001)$.

\section{Moderate or Severe Headache Days}

The mean (SD) number of moderate or severe headache days per month at baseline, as self-reported by study participants, was 12.9 (7.7) days (Figure 3C). Moderate or severe headache days were reduced following onabotulinumtoxinA treatment (Figure 3D), with a mean (SD) change of 5.6 (7.0) fewer days at Tx4 than baseline (all time points statistically significant, $p<0.0001$ ). Similarly, study completers reported a mean (SD) of 11.3 (6.8) moderate or severe headache days per month at baseline, but continued to report statistically significant reductions in moderate or severe headache days following onabotulinumtoxinA treatment (Tx1 [ $\mathrm{n}=109]:-3.6$ [7.0], Tx2 [n=107]: -3.5 [6.9], Tx3 [n=110]: -5.0 [7.0], Tx4 [n=107]: -5.3 [6.7], Tx7/Final Visit $[n=103]$ : -4.7 [7.7]; all comparisons versus baseline, $p<0.0001$ ).

\section{Clinician's Global Impression of Change (CGIC)}

Following onabotulinumtoxinA treatment, $96.6 \%(n=145 / 150)$ of participants were rated as improved ("very much improved": $33.3 \%$ [n=50], "much improved": 46.0\% [n=69], "minimally 

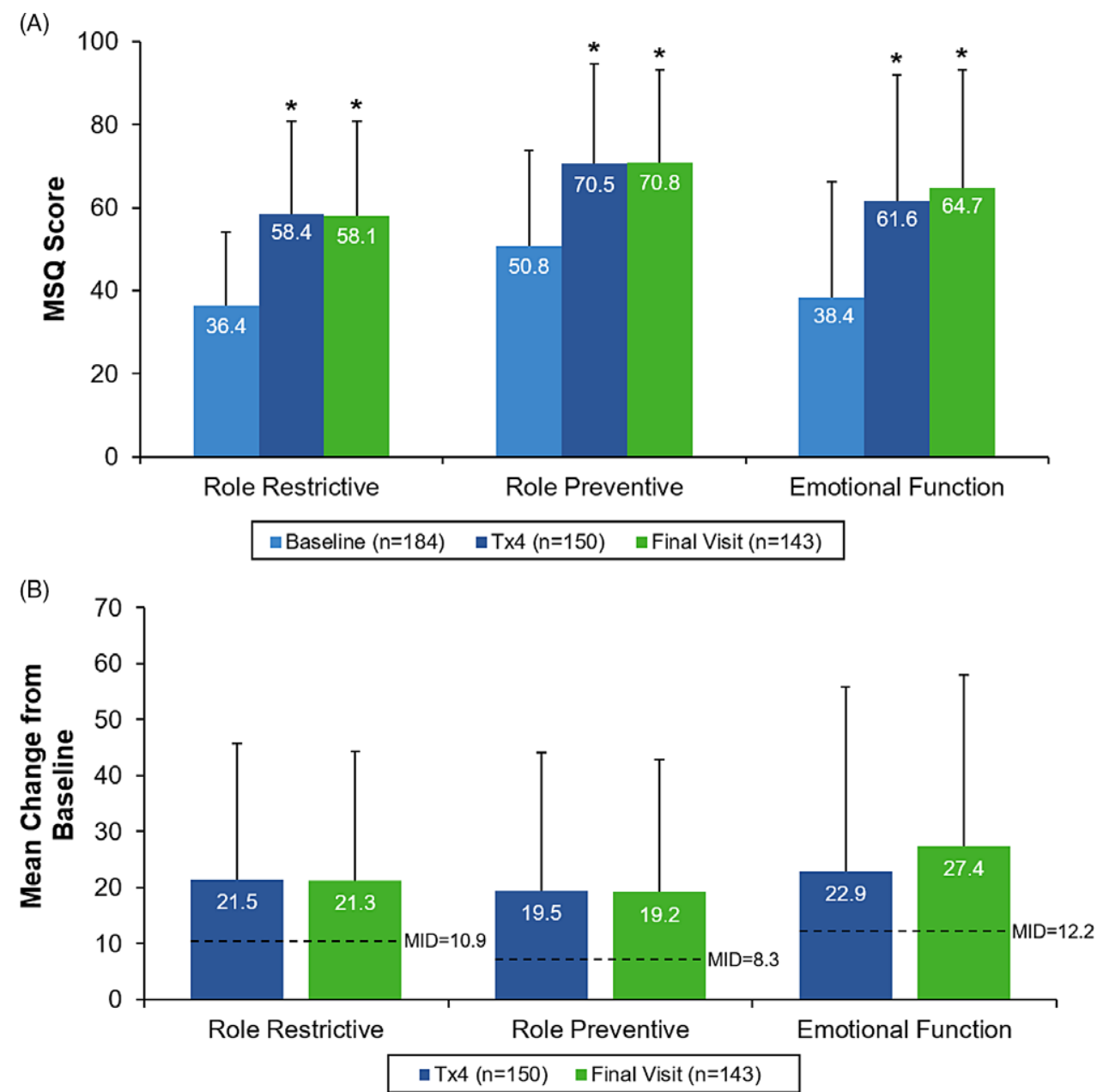

Figure 2: Patient-reported Migraine-Specific Quality of Life Questionnaire (MSQ) following onabotulinumtoxinA treatment for chronic migraine $(C M)$.

(A) Mean MSQ scores at baseline $(n=184), T \times 4(n=150)$, and the final visit $(n=143$, role restrictive and role preventive domains; $n=142$, emotional function). (B) Mean change from baseline in MSQ for each domain (i.e., role restrictive, role preventive, and emotional function) are shown at $T x 4(n=150)$ and the final visit ( $n=143$, role restrictive and role preventive domains; $n=142$, emotional function); withingroup minimal important differences for MSQ v. 2.1 are displayed for reference ${ }^{37}$. Missing data include 41 participants at the final visit for role function-restrictive and role function-preventive dimensions and 42 participants at the final visit for emotional function dimension. Error bars represent standard deviations. Statistical significance is shown as * $\mathrm{p}<0.0001$. n, number of participants; Tx, treatment.

improved": $17.3 \%[\mathrm{n}=26]$, "no change": $2.7 \%[\mathrm{n}=4]$, "minimally worse": $0.0 \%[\mathrm{n}=0]$, "much worse": $0.7 \%[\mathrm{n}=1]$, "very much worse": $0.0 \%[\mathrm{n}=0]$ ) by physicians at $\mathrm{Tx} 4$ compared with baseline. At Tx7/Final Visit, 86.9\% ( $\mathrm{n}=139 / 160)$ of participants were rated as improved ("very much improved": 43.1\% [n=69], "much improved": $34.4 \%[\mathrm{n}=55]$, "minimally improved": $9.4 \%[\mathrm{n}=15]$, "no change": $12.5 \%[\mathrm{n}=20]$, "minimally worse": $0.0 \%[\mathrm{n}=0]$, "much worse": $0.6 \%[\mathrm{n}=1]$, "very much worse": $0.0 \%[\mathrm{n}=0]$, data missing for $\mathrm{n}=24$ participants) by physicians compared with baseline.

In study completers, $100.0 \%(n=123 / 123)$ of participants were rated as improved ("very much improved": $37.4 \%$ [n=46], "much improved": $48.8 \%[\mathrm{n}=60]$, "minimally improved": $13.8 \%$ [n=17], "no change": $0.0 \%$ [n=0], "minimally worse": $0.0 \%[\mathrm{n}=0]$, "much worse": $0.0 \%[\mathrm{n}=0]$, "very much worse": $0.0 \%[\mathrm{n}=0]$ ) by physicians at $\mathrm{Tx} 4$ compared with baseline. At Tx7/Final Visit, 98.4\% $(n=121 / 123)$ of participants were rated as improved ("very much improved": $50.4 \%$ [n=62], "much improved": $42.3 \%$ [n = 52], "minimally improved": $5.7 \%$ [n=7], "no change": $1.6 \%[\mathrm{n}=2]$, "minimally worse": $0.0 \%$ $[\mathrm{n}=0]$, "much worse": $0.0 \%[\mathrm{n}=0]$, "very much worse": $0.0 \%$ $[\mathrm{n}=0])$ by physicians compared with baseline.

\section{Patient Global Assessment of Treatment}

To assess the effectiveness of onabotulinumtoxinA treatment for CM, study participants were asked a series of questions at Tx2, Tx3, Tx4, and Tx7. A high percentage of participants (range: $83 / 174,47.7 \%$ [Tx2] to $101 / 127,79.5 \%$ [Tx7]) responded that they were satisfied or very satisfied with the ability of onabotulinumtoxinA to control the frequency of their headaches throughout the course of the study (Figure 4A). Similarly, at all treatments, the majority of participants (range: 91/174, 52.3\% 

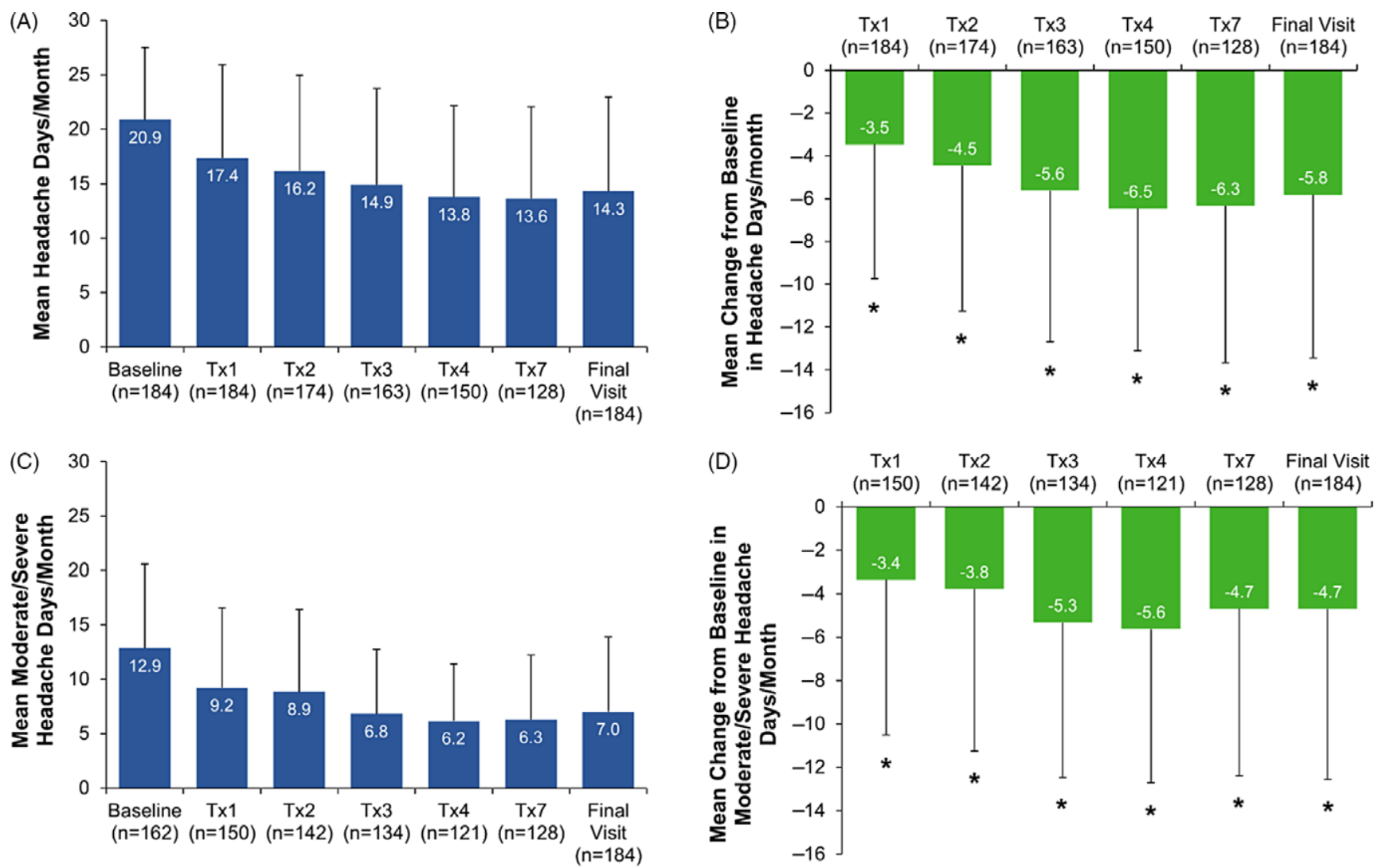

Figure 3: Headache day frequency following onabotulinumtoxinA treatment for CM.

(A) Number of headache days per month and $(B)$ change from baseline in headache days are shown. In addition, $(C)$ number of moderate or severe headache days per month and $(D)$ change from baseline in moderate or severe headache days are shown. A headache day was defined as a headache severity score $\geq 1$, and a moderate or severe headache day was defined as a headache severity score $\geq 5$ (moderate pain or greater), as entered daily into the headache diary by the study participant. A month was defined as a 28-day period. Error bars represent standard deviations. Statistical significance is shown as *p $<0.0001$. Missing data include 22 participants at baseline, 34 participants at Tx1, 32 participants at Tx2, 29 participants at Tx3, 29 participants at Tx4, 24 participants at Tx7, and 58 participants at the final visit. $n$, number of participants; Tx, treatment. Participants with $<5$ d of diary data available for days 57 through 84 analysis windows were set to missing.

[Tx2] to $106 / 127,83.5 \%$ [Tx7]) responded that they were satisfied or very satisfied with the ability of onabotulinumtoxinA to control the severity of their headaches (Figure 4B). Finally, the majority of participants (range: 96/174, 55.2\% [Tx2] to 109/127, $85.8 \%$ [Tx7]) were satisfied or very satisfied with their injection medication (onabotulinumtoxinA) during the past three months (Figure 4C).

Of the study completers, the majority of participants responded that they were satisfied or very satisfied with: the ability of onabotulinumtoxinA to control the frequency of their headaches (range: $64 / 123,52.0 \%$ [Tx2], to 98/120, 81.6\% [final visit]), to control the severity of their headaches (range: 73/123, $59.4 \%$ [Tx2] to $103 / 123,83.7 \%$ [Tx7]), and with their injection medication (onabotulinumtoxinA) during the past three months (range: $77 / 123,62.7 \%$ [Tx2] to $104 / 120,86.7 \%$ [final visit]).

\section{Safety and Tolerability}

In the PREDICT study, there were 168 TEAEs reported in $77 / 184$ participants (41.8\%; Table 3), with 38 events in 22/184 participants $(12.0 \%)$ considered treatment-related (Table 3). The most common treatment-related TEAE was eyelid ptosis, with 9 events reported in $8 / 184$ participants $(4.3 \%)$. In total, there were 6 serious TEAEs reported in 4/184 participants (2.2\%; Table 3), with none considered treatment-related. No TEAEs were adjudicated as possible distant spread of toxin. No deaths were reported in this study. Overall, $3 / 184$ participants (1.6\%) discontinued the study due to a TEAE, including one case each of sinusitis, colon cancer, and migraine.

\section{Discussion}

The PREDICT study aimed to prospectively assess real-world long-term health-related quality of life in adults with CM treated with onabotulinumtoxinA in Canada using physician- and patient-reported outcomes in an open-label design over an approximately two-year period (seven treatment cycles). Additional goals included the assessment of headache-related disability, efficacy, and tolerability of onabotulinumtoxinA for the treatment of CM. Real-world evidence from PREDICT demonstrates that onabotulinumtoxinA for $\mathrm{CM}$ reduced headache day frequency and severity, improved health-related quality of life as determined by MSQ, and was associated with high physician and patient satisfaction. Long-term clinical use of onabotulinumtoxinA was well-tolerated with no new safety signals identified. 
(A)

Since last injection, satisfaction with ability of
otulinumtoxinA to control frequency of headaches

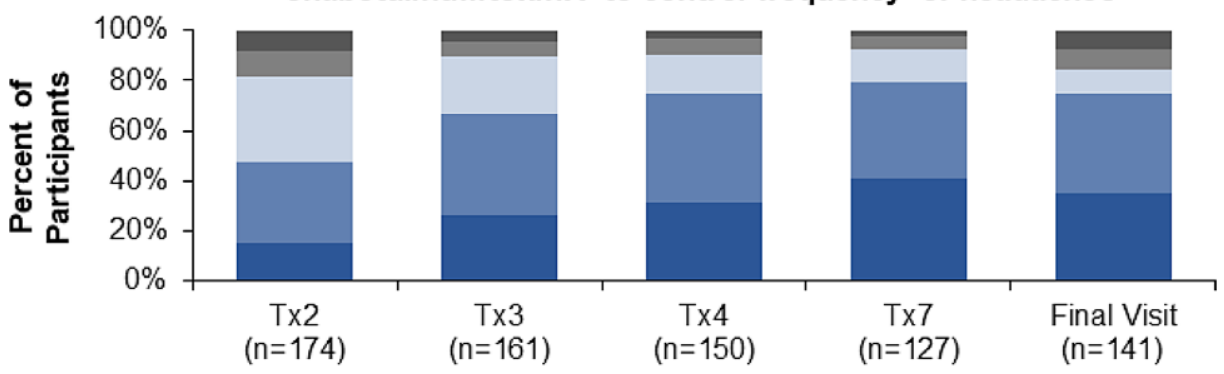

(B)

Since last injection, satisfaction with ability of onabotulinumtoxin A to control severity of headaches

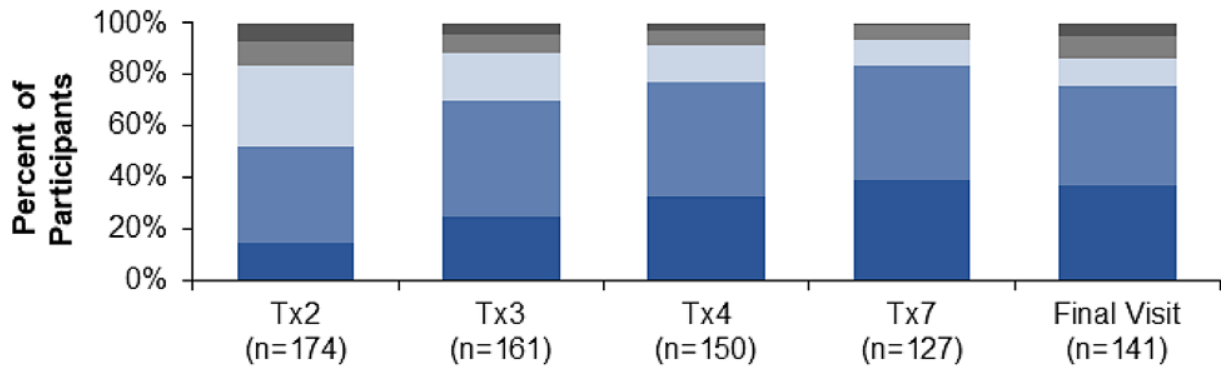

(C)

During past 3 months, satisfaction with (onabotulinumtoxinA) injection medication

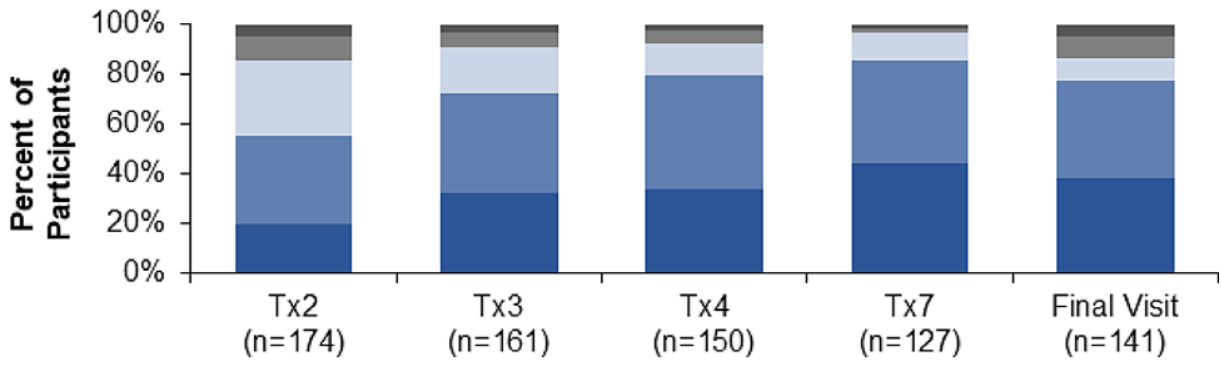

$\square(5)$ Very satisfied $\square(4) \quad(3)$ Neither satisfied nor dissatisfied $\square(2) \quad \square(1)$ Very dissatisfied

Figure 4: Patient-reported satisfaction with onabotulinumtoxinA for the treatment of CM.

Participants were asked a series of questions to determine their satisfaction with onabotulinumtoxinA (referred to as BOTOX in the original questionnaire) treatment for CM at each following treatment. Data represent the percentage of participants that were "very dissatisfied" (1) to "very satisfied" (5). Missing data include 2 participants at Tx3, 1 participant at TX7, and 43 participants at the final visit for panels (A)-(C). n, number of participants; Tx, treatment.

In agreement with previous findings, ${ }^{30}$ real-world onabotulinumtoxinA utilization largely adhered to the injection regimen for $\mathrm{CM}$ described in the Canadian onabotulinumtoxinA product monograph (version July $7,2014^{33}$ ) and as outlined in the PREEMPT clinical program. ${ }^{31,32}$ Across all treatment visits, study participants received a mean dose of approximately $170 \mathrm{U}$ of onabotulinumtoxinA, which is within the range reported in other real-world onabotulinumtoxinA preventive studies. ${ }^{30,38}$ In the REPOSE study, ${ }^{30}$ participants received a mean (SD) 155.1 (21.4) U of onabotulinumtoxinA. At each PREDICT treatment visit, approximately $20 \%$ of participants received between $195-$ $200 \mathrm{U}$ of onabotulinumtoxinA. On average, the majority of study participants received onabotulinumtoxinA at a dosing interval slightly greater than twelve weeks, which may be due to scheduling difficulties in clinic. This interval, however, is consistent with the product monograph recommendation of twelve weeks. $^{33}$

When assessing response to treatment, improvements in quality of life, such as physical and emotional functioning, are important to consider and may or may not be associated with significant reductions in headache days. ${ }^{39,40}$ In the PREDICT study, the primary endpoint was the mean change in MSQ between baseline and Tx4. Following treatment with onabotulinumtoxinA, PREDICT participants reported significantly higher MSQ scores, exceeding MIDs for all three domains: role restrictive, role preventive, and emotional function, which is supported by previous clinical and observational onabotulinumtoxinA studies. $^{26,30,38}$ 


\section{Table 3: Treatment-emergent adverse events $\dagger$}

\begin{tabular}{|c|c|c|}
\hline & Participants, n (\%) & Events, $\mathbf{n}$ \\
\hline \multicolumn{3}{|l|}{ TEAEs } \\
\hline $\begin{array}{l}\text { Upper respiratory tract } \\
\text { infection }\end{array}$ & $8(4.3)$ & 11 \\
\hline Eyelid ptosis & $8(4.3)$ & 9 \\
\hline Neck pain & $8(4.3)$ & 9 \\
\hline Nasopharyngitis & $7(3.8)$ & 7 \\
\hline Sinusitis & $6(3.3)$ & 7 \\
\hline Bronchitis & $6(3.3)$ & 6 \\
\hline Pneumonia & $5(2.7)$ & 5 \\
\hline Brow ptosis & $4(2.2)$ & 6 \\
\hline \multicolumn{3}{|l|}{ Serious TEAEs } \\
\hline Central pain syndrome & $1(0.5)$ & 2 \\
\hline Colon cancer & $1(0.5)$ & 1 \\
\hline $\begin{array}{l}\text { Idiopathic intracranial } \\
\text { hypertension }\end{array}$ & $1(0.5)$ & 1 \\
\hline Seizure & $1(0.5)$ & 1 \\
\hline Syncope & $1(0.5)$ & 1 \\
\hline \multicolumn{3}{|l|}{ Treatment-related TEAEs ${ }^{\ddagger}$} \\
\hline Eyelid ptosis & $8(4.3)$ & 9 \\
\hline Brow ptosis & $4(2.2)$ & 6 \\
\hline Muscle spasms & $3(1.6)$ & 4 \\
\hline Muscle tightness & $3(1.6)$ & 4 \\
\hline Neck pain & $3(1.6)$ & 4 \\
\hline Muscular weakness & $2(1.1)$ & 2 \\
\hline Eye swelling & $1(0.5)$ & 1 \\
\hline Head discomfort & $1(0.5)$ & 1 \\
\hline Headache & $1(0.5)$ & 1 \\
\hline Lacrimation increased & $1(0.5)$ & 1 \\
\hline $\begin{array}{l}\text { Musculoskeletal } \\
\text { discomfort }\end{array}$ & $1(0.5)$ & 1 \\
\hline Musculoskeletal pain & $1(0.5)$ & 1 \\
\hline Musculoskeletal stiffness & $1(0.5)$ & 1 \\
\hline Pain in jaw & $1(0.5)$ & 1 \\
\hline Trismus & $1(0.5)$ & 1 \\
\hline
\end{tabular}

n, number of participants or events; TEAE, treatment-emergent adverse events

${ }^{\dagger}$ TEAEs occurring in $>2 \%$ of participants are shown; all serious TEAEs and treatment-related TEAEs are shown

${ }^{\ddagger}$ Treatment-related TEAEs were defined as events determined by the investigator to have a reasonable relationship to treatment and are presented as overall counts and percentages by preferred term. Some events may appear multiple times based on their relationship to treatment

On average, study participants self-reported $\sim 21$ headache days/month and $\sim 13$ moderate or severe headache days/month in the daily headache diary at baseline. Following onabotulinumtoxinA treatment, participants experienced a significant reduction in headache days, with an average of $6.5(31 \%)$ fewer headache days/month and 5.6 (43\%) fewer moderate or severe headache days/month at $\mathrm{Tx} 4$. In the $\mathrm{CM}$ population, $\mathrm{a} \geq 30 \%$ responder rate is considered clinically meaningful. ${ }^{41}$ Evidence from the PREEMPT clinical trial program shows that even if patients do not experience a reduction in headache days, reduction in headache severity has a clinically meaningful impact on quality of life. ${ }^{42}$

Satisfaction data demonstrate that the majority of physicians and participants were satisfied with onabotulinumtoxinA treatment for CM throughout the course of the PREDICT study. The proportion of physicians that rated participants as "very much improved" (highest rating on the CGIC) increased from 33.3\% at Tx4 to $43.1 \%$ at the final visit. Similarly, the proportion of participants that reported that they were "satisfied" or "very satisfied" with the ability of onabotulinumtoxinA to control the frequency of headaches $(47.7 \%$ at treatment 2 to $79.5 \%$ at treatment 7) and control the severity of headaches $(52.3 \%$ at treatment 2 to $83.5 \%$ at treatment 7) increased over time. In addition, the majority of participants at each treatment session reported that they were "satisfied" or "very satisfied" with their injection medication during the past three months $(55.1 \%$ at treatment 2 to $85.8 \%$ at treatment 7 ). Inclusion of the completer data affirms that increases in physician and participant satisfaction with repeated onabotulinumtoxinA treatment were not simply due to individuals with unfavorable results discontinuing the study, but instead, that individuals who stayed on treatment experienced improved outcomes with long-term use.

In the PREDICT study, long-term onabotulinumtoxinA preventive treatment was reported to be safe and well-tolerated by a wide population of adults in Canada with CM. The majority of TEAEs reported in PREDICT were mild to moderate in severity and were comparable with the PREEMPT, ${ }^{26}$ COMPEL,${ }^{29}$ and REPOSE $^{30}$ studies. The most commonly reported treatmentrelated TEAEs in PREDICT were eyelid ptosis $(8 / 184 ; 4.3 \%$ of participants), brow ptosis $(4 / 184 ; 2.2 \%)$, muscle spasms $(3 / 184$; $1.6 \%)$, muscle tightness $(3 / 184 ; 1.6)$, and neck pain $(3 / 183$; $1.6 \%$ ). No serious TEAEs reported in PREDICT were considered treatment related. Overall, the discontinuation rate for PREDICT was $38 \%$, which primarily involved being lost to follow-up and other, nonspecific reasons, likely reflecting the length and design of the study. In comparison, the rate of discontinuation in PREEMPT was $25 \%-30 \%$ in the fifty-six-week open-label phase. ${ }^{26}$ The number of participants that discounted the study due to an $\mathrm{AE}$ was low $(\mathrm{n}=3)$ and no deaths were reported. Additional information collected from the withdrawal questionnaire is summarized in Supplemental Table 3. Similar to conclusions in COMPEL, ${ }^{29}$ the inclusion of study participants who used medication(s) with a known preventive effect did not appear to negatively impact the safety profile of onabotulinumtoxinA.

There are limitations inherent to long-term observational studies, including the lack of a placebo or comparator arm, recall bias, and participant drop-off due to the length of the study. The lack of a control arm precludes differentiation of treatmentrelated events versus those that would have occurred naturally. In addition, the participants remaining in the study at later time points likely reflect the participants who found onabotulinumtoxinA treatment to be effective and tolerable. The initial estimated participant dropout rate of $\sim 10 \%$ was an underestimation and is possibly attributable to study fatigue and the impact on the participants in this study, which could have potentially affected 
the final results. In the PREDICT study, not all outcomes were collected at each treatment visit (e.g., MSQ and physician satisfaction were collected only at Tx4 and final visit), and no data were collected at treatments 5 and 6 , to reduce the burden imposed on study participants and site investigators. The lack of data at each treatment visit may restrict the types of analyses/ statistical questions that can be determined from this dataset (e.g., changes in the pattern of onabotulinumtoxinA utilization). Selfreported measures, such as the headache diary or MSQ, rely on the participation and memory recall of study participants, which could lead to data errors or inconsistencies. Nonetheless, these patient-reported outcome data are comparable with other published observational studies. ${ }^{29,30}$ Exclusion of participants with moderate or severe depression according to the Beck Depression Inventory (BDI-II score of $>24^{43}$ ) may limit the applicability of these findings to this group of individuals.

Despite limitations inherent to observational studies, data from the PREDICT study have high generalizability to clinical practice and add to the wealth of real-world, long-term data on onabotulinumtoxinA treatment in CM around the world. Participant demographic data (e.g., gender, medication use history) are similar to previous clinical and real-world studies of the effectiveness of onabotulinumtoxinA for the treatment of $\mathrm{CM}^{26,29,30,44-49}$ The PREDICT study allowed for the inclusion of participants using medication(s) with a known headache preventive effect, which is reflective of real-world CM treatment strategies where physicians may prescribe one or more headache preventive medications concurrently. ${ }^{14}$ Future analyses from PREDICT will explore the impact of onabotulinumtoxinA treatment for $\mathrm{CM}$ on health resource utilization and medication overuse.

\section{Conclusions}

Real-world evidence from PREDICT demonstrates that onabotulinumtoxinA treatment for CM for up to two years (seven treatment cycles) improved health-related quality of life and reduced headache frequency and severity, with high physician and participant satisfaction. Although the limitation of the study design, namely that participants who were satisfied with the treatment were more likely to be completers, and the $>30 \%$ discontinuation rate may have biased these outcomes, these results add to the body of evidence supporting the long-term safety and effectiveness of onabotulinumtoxinA for CM.

\section{ACKNOWLEDGMents}

The authors sincerely thank the patients who participated in this study. Thank you to the PREDICT study investigators: Dr. Hany Demian, Dr. Pankaj Dhawan, Dr. Rose Giammarco, Dr. Jeff Oyler, Dr. Viera Saly, Dr. Gary Shapero, Dr. Brad Stewart, Dr. Martin Veilleux, and Dr. Theodore Wein. Thank you to Chris Sigouin, an employee of ClinWest, for completing the statistical analyses. Medical writing was provided to the authors by Kristin M. Hirahatake, PhD, and Monica R.P. Elmore, $\mathrm{PhD}$, of AbbVie. Editorial assistance was provided by Peloton Advantage, LLC, an OPEN Health company, Parsippany, NJ, and was funded by AbbVie. All authors met the ICMJE authorship criteria. Neither honoraria nor any other form of compensation was provided for authorship.

\section{FUNDING}

This study was sponsored by Allergan (prior to its acquisition by AbbVie), Markham, Ontario, Canada.

\section{Clinical Trial Registration \\ PREDICT (NCT02502123).}

\section{Disclosures}

Dr. GB received compensation for consulting, honoraria, and/or research support from Allergan (now AbbVie), Lilly, Novartis, and Teva. Dr. IF received compensation for consulting and/or honoraria from Allergan (now AbbVie), Aralez, Lilly, Novartis, Nuvo, and Teva. Dr. CG received compensation for consulting and/or honoraria from Allergan (now AbbVie), Aralez, Amgen/Novartis, and Lilly. Dr. MO received compensation for consulting and/or honoraria from Cannimed and Spectrum Canada. Dr. SC received compensation for consulting and/or honoraria from Allergan (now AbbVie), Lilly, Novartis, and Teva, and received research support from Novartis. Dr. KS, Ms. MB, and Dr. GD are full-time employees of AbbVie. Dr. KS and Dr. GD own stock or stock options in AbbVie. Dr. WJB received compensation for consulting and/or honoraria from Allergan (now AbbVie), Aralez, Eli Lilly \& Co., Lundbeck, Novartis, and Weber and Weber.

\section{Statement OF AUTHORShIP}

All authors participated in study conception and design. GB, IF, CG, MO, SC, and WJB participated in data acquisition. All authors participated in data analysis and interpretation. All authors reviewed, revised the manuscript for intellectual content, and approved the final manuscript.

\section{Data Sharing Statement}

AbbVie is committed to responsible data sharing regarding the clinical trials we sponsor. This includes access to anonymized, individual and trial-level data (analysis datasets), as well as other information (e.g., protocols and Clinical Study Reports), as long as the trials are not part of an ongoing or planned regulatory submission. This includes requests for clinical trial data for unlicensed products and indications.

This clinical trial data can be requested by any qualified researchers who engage in rigorous, independent scientific research, and will be provided following review and approval of a research proposal and Statistical Analysis Plan (SAP) and execution of a Data Sharing Agreement (DSA). Data requests can be submitted at any time and the data will be accessible for 12 months, with possible extensions considered. For more information on the process, or to submit a request, visit the following link: https://www.abbvie.com/our-science/clinical-trials/clinicaltrials-data-and-information-sharing/data-and-information-sharingwith-qualified-researchers.html.

\section{Supplementary Material}

To view supplementary material for this article, please visit https://doi.org/10.1017/cjn.2021.153. 


\section{REFERENCES}

1. Headache Classification Committee of the International Headache Society (IHS), The International Classification of Headache Disorders, 3rd edition (beta version). Cephalalgia. 2013;33:629-808.

2. Natoli JL, Manack A, Dean B, et al. Global prevalence of chronic migraine: a systematic review. Cephalalgia. 2010;30:599-609.

3. Silberstein SD. Migraine. Lancet. 2004;363:381-91.

4. Burch RC, Buse DC, Lipton RB. Migraine: epidemiology, burden, and comorbidity. Neurol Clin. 2019;37:631-49.

5. Buse DC, Fanning KM, Reed ML, et al. Life with migraine: effects on relationships, career, and finances from the chronic migraine epidemiology and outcomes (CaMEO) study. Headache. 2019; 59:1286-99.

6. Buse DC, Scher AI, Dodick DW, et al. Impact of migraine on the family: perspectives of people with migraine and their spouse/ domestic partner in the CaMEO study. Mayo Clin Proc. 2016; 91:596-611.

7. Hawkins K, Wang S, Rupnow M. Direct cost burden among insured US employees with migraine. Headache. 2008;48:553-63.

8. Messali A, Sanderson JC, Blumenfeld AM, et al. Direct and indirect costs of chronic and episodic migraine in the United States: a web-based survey. Headache. 2016;56:306-22.

9. Millson DS, Tepper SJ, Rapoport AM. Migraine pharmacotherapy with oral triptans: a rational approach to clinical management. Expert Opin Pharmacother. 2000;1:391-404.

10. Dodick DW, Loder EW, Manack Adams A, et al. Assessing barriers to chronic migraine consultation, diagnosis, and treatment: results from the chronic migraine epidemiology and outcomes (CaMEO) study. Headache. 2016;56:821-34.

11. Bigal ME, Serrano D, Reed M, Lipton RB. Chronic migraine in the population: burden, diagnosis, and satisfaction with treatment. Neurology. 2008;71:559-66.

12. Lipton RB, Serrano D, Holland S, Fanning KM, Reed ML, Buse DC. Barriers to the diagnosis and treatment of migraine: effects of sex, income, and headache features. Headache. 2013;53:81-92.

13. Starling AJ, Dodick DW. Best practices for patients with chronic migraine: burden, diagnosis, and management in primary care. Mayo Clin Proc. 2015;90:408-14.

14. Schwedt TJ. Preventive therapy of migraine. Continuum (Minneap Minn). 2018;24:1052-65.

15. Escher CM, Paracka L, Dressler D, Kollewe K. Botulinum toxin in the management of chronic migraine: clinical evidence and experience. Ther Adv Neurol Disord. 2017;10:127-35.

16. Diener HC, Holle D, Solbach K, Gaul C. Medication-overuse headache: risk factors, pathophysiology and management. Nat Rev Neurol. 2016;12:575-83.

17. Limmroth V, Katsarava Z, Fritsche G, Przywara S, Diener HC. Features of medication overuse headache following overuse of different acute headache drugs. Neurology. 2002;59:1011-4.

18. Creac'h C, Radat F, Mick G, et al. One or several types of triptan overuse headaches? Headache. 2009;49:519-28.

19. Becker WJ, Findlay T, Moga C, Scott NA, Harstall C, Taenzer P. Guideline for primary care management of headache in adults. Can Fam Physician. 2015;61:670-9.

20. Becker WJ. The diagnosis and management of chronic migraine in primary care. Headache. 2017;57:1471-81.

21. Raffaelli B, Neeb L, Reuter U. Monoclonal antibodies for the prevention of migraine. Expert Opin Biol Ther. 2019; 19:1307-17.

22. Charles A, Pozo-Rosich P. Targeting calcitonin gene-related peptide: a new era in migraine therapy. Lancet. 2019;394:1765-74.

23. Ceriani CEJ, Wilhour DA, Silberstein SD. Novel medications for the treatment of migraine. Headache. 2019;59:1597-608.

24. Burstein R, Blumenfeld AM, Silberstein SD, Manack Adams A, Brin MF. Mechanism of action of onabotulinumtoxinA in chronic migraine: a narrative review. Headache. 2020;60:1259-72.

25. Aurora SK, Dodick DW, Turkel CC, et al. OnabotulinumtoxinA for treatment of chronic migraine: results from the double-blind, randomized, placebo-controlled phase of the PREEMPT 1 trial. Cephalalgia. 2010;30:793-803.
26. Aurora SK, Winner P, Freeman MC, et al. OnabotulinumtoxinA for treatment of chronic migraine: pooled analyses of the 56-week PREEMPT clinical program. Headache. 2011;51:1358-73.

27. Diener HC, Dodick DW, Aurora SK, et al. OnabotulinumtoxinA for treatment of chronic migraine: results from the double-blind, randomized, placebo-controlled phase of the PREEMPT 2 trial. Cephalalgia. 2010;30:804-14.

28. Dodick DW, Turkel CC, DeGryse RE, et al. OnabotulinumtoxinA for treatment of chronic migraine: pooled results from the doubleblind, randomized, placebo-controlled phases of the PREEMPT clinical program. Headache. 2010;50:921-36.

29. Blumenfeld AM, Stark RJ, Freeman MC, Orejudos A, Manack Adams A. Long-term study of the efficacy and safety of Onabotulinumtoxin A for the prevention of chronic migraine: COMPEL study. J Headache Pain. 2018;19:13.

30. Ahmed F, Gaul C, Garcia-Monco JC, Sommer K, Martelletti P, Investigators RP. An open-label prospective study of the real-life use of onabotulinumtoxinA for the treatment of chronic migraine: the REPOSE study. J Headache Pain. 2019;20:26.

31. Blumenfeld A, Silberstein SD, Dodick DW, Aurora SK, Turkel CC, Binder WJ. Method of injection of onabotulinumtoxinA for chronic migraine: a safe, well-tolerated, and effective treatment paradigm based on the PREEMPT clinical program. Headache. 2010;50:1406-18.

32. Blumenfeld AM, Silberstein SD, Dodick DW, Aurora SK, Brin MF, Binder WJ. Insights into the functional anatomy behind the PREEMPT injection paradigm: guidance on achieving optimal outcomes. Headache. 2017;57:766-77.

33. Botox [product monograph]. Markham, ON, Canada: Allergan; 2014.

34. Jhingran P, Osterhaus JT, Miller DW, Lee JT, Kirchdoerfer L. Development and validation of the migraine-specific quality of life questionnaire. Headache. 1998;38:295-302.

35. Martin BC, Pathak DS, Sharfman MI, et al. Validity and reliability of the migraine-specific quality of life questionnaire (MSQ Version 2.1). Headache. 2000;40:204-15.

36. Cole JC, Lin P, Rupnow MF. Validation of the migraine-specific quality of life questionnaire version 2.1 (MSQ v. 2.1) for patients undergoing prophylactic migraine treatment. Qual Life Res. 2007; 16:1231-37.

37. Dodick DW, Silberstein S, Saper J, et al. The impact of topiramate on health-related quality of life indicators in chronic migraine. Headache. 2007;47:1398-408.

38. Kollewe K, Escher CM, Wulff DU, et al. Long-term treatment of chronic migraine with OnabotulinumtoxinA: efficacy, quality of life and tolerability in a real-life setting. J Neural Transm (Vienna, Austria: 1996). 2016;123:533-40.

39. National Institute for Health and Care Excellence (NICE). Botulinum toxin type A for the prevention of headaches in adults with chronic migraine; 2012. Available at: https://www. nice.org.uk/guidance/ta260/chapter/1-Guidance. Accessed on July 26, 2021.

40. Dodick DW, Turkel CC, DeGryse RE, et al. Assessing clinically meaningful treatment effects in controlled trials: chronic migraine as an example. J Pain. 2015;16:164-75.

41. Silberstein S, Tfelt-Hansen P, Dodick DW, et al. Guidelines for controlled trials of prophylactic treatment of chronic migraine in adults. Cephalalgia. 2008;28:484-95.

42. Matharu M, Halker R, Pozo-Rosich P, DeGryse R, Manack Adams A, Aurora SK. The impact of onabotulinumtoxinA on severe headache days: PREEMPT 56-week pooled analysis. J Headache Pain. 2017;18:78.

43. Beck AT, Steer RA, Brown GK. Manual for the Beck Depression Inventory-II. San Antonio, TX: Psychological Corporation; 1996.

44. Lipton RB, Manack Adams A, Buse DC, Fanning KM, Reed ML. A comparison of the chronic migraine epidemiology and outcomes (CaMEO) study and American migraine prevalence and prevention (AMPP) study: demographics and headache-related disability. Headache. 2016;56:1280-9.

45. Stark C, Stark R, Limberg N, et al. Real-world effectiveness of onabotulinumtoxinA treatment for the prevention of headaches in 
adults with chronic migraine in Australia: a retrospective study. $\mathrm{J}$ Headache Pain. 2019;20:81.

46. Andreou AP, Trimboli M, Al-Kaisy A, et al. Prospective real-world analysis of OnabotulinumtoxinA in chronic migraine post-National Institute for Health and Care Excellence UK technology appraisal. Eur J Neurol. 2018;25:1069-e83.

47. Khalil M, Zafar HW, Quarshie V, Ahmed F. Prospective analysis of the use of OnabotulinumtoxinA (BOTOX) in the treatment of chronic migraine; real-life data in 254 patients from Hull, U.K. J Headache Pain. 2014;15:54.
48. Vernieri F, Paolucci M, Altamura C, et al. OnabotulinumtoxinA for chronic migraine: a real-life Italian multicenter experience. Neurol Sci. 2018;39:171-2.

49. Vikelis M, Argyriou AA, Dermitzakis EV, Spingos KC, Mitsikostas DD. Onabotulinumtoxin-A treatment in Greek patients with chronic migraine. J Headache Pain. 2016;17:84.

50. Jaeschke R, Singer J, Guyatt GH. Measurement of health status. Ascertaining the minimal clinically important difference. Control Clin Trials. 1989;10:407-15. 